\title{
The Methods to Cope with Children's Shyness
}

\author{
Ali Rahravan \\ Bachelor Student of Educational Sciences, Shahid Motahari University, Fars \\ Email:rahravanali73@yahoo.com
}

\section{Doi:10.5901/mjss.2016.v7n4s1p215}

\begin{abstract}
Social education, raising children's skills and prevention of any social disabilities especially the treatment of shyness are the main responsibilities of parents. Having healthy children has been always important for parents, so that the problem of shyness and its treatment has been one of the most important problems of parents. The researcher in this article targeted parents to provide some key methods and principles for better education and the removal of shyness in children. We hope to study the creating factors of shyness and the importance to cope with it more than ever. So that parents can use appropriate methods to educate and bring up their children, introduce healthy children to society and make success in their lives.
\end{abstract}

Keywords: reduce of shyness, parents and shyness, children's shyness; cope with shyness, prevention of shyness

\section{Introduction}

One of the problems of most children and teenagers is the sense of shyness. Shyness means feeling uncomfortable in a group. Shy children become anxious in unfamiliar situations and while talking to others. (Salahshur 1393) In other words, shyness means extra self attention and the fear to face the others. Because shyness is a type of social phobia or anxiety in which the person runs away from facing unfamiliar people and social communications. Shyness is a type of social disability and each one of us may feel that we are alone in a specific situation. (Afrouz 1381) In other words, shyness is a disorder that makes children and teenagers escape from communicating with people and the outside environment. These children and teenagers have no intimate and close friends because their mental and emotional interests in the others decrease. A shy teenager avoids participating in group activities and spends time only with his/her single friend on whom he/she is so much depended. Shyness is one of the relative behaviors that annoy people so much. If it is not treated, the teenager will be led to other problems like the lack of self confidence, depression, anxiety and irritability. The lack of feeling empowered, self confidence and also the inability to show and express feelings, the express of thoughts and opinions separate the person from group activities. (Morad Hasel 1382)

Shyness is one of the serious problems of children, although it may not be so serious according to teachers and sometimes parents, although shyness does not cause any problem for his/her teachers but may be the unhappiest child due to the sense of insecurity and incompetence in him/herself. Although, not all shy children will suffer from mental disease in the future, some of them will suffer or at least they will become unhappy and incompetent adults in society. This reason is enough to consider the shyness of children. The symptoms of shyness are: shyness, silence, sense of deprivation and inability to establish a relationship with friends and teachers, delaying the works, impatience, fatigue, absurdity, Irritability, fear of future, not asking for help while there is a need, Compromise with the current situation, and not objecting to it even in case of feeling anxious, avoiding competition, absence in school and showing no interest in lessons, lack of concentration, sleeping and eating disorder, ignoring the events happening around, lack of confidence in a successful experience in group activity. (Kalhori 1389) A psychologist says: I suffered from shyness for years and was not satisfied with participating in a group activity. I had Tongue tie and could not do anything whenever I participated in associations or groups. I felt anxious and uncomfortable to stand in front of them and talk to them. I always looked for excuses to escape from those groups or associations that made me uncomfortable. (Saeedi 1355) This study attempts to provide some principles to fight against shyness in children and prevent it.

\section{Do Not Mix up Shyness with Modesty}

Firstly, we should consider the principle that shyness is undoubtedly different from modesty. Some people consider shyness as a positive and normal trait for girls and women and think that that these girls are modest and even encourage 
them. On the other hand, shyness is considered as an inappropriate behavior for boys. Modesty is one of the voluntary and valuable traits of transcendent people while shyness is an involuntary and unpleasant phenomenon that indicates social disability that is unpleasant for both genders. Family and society should know and indentify the difference between shyness and modesty. Modesty is not the lack of participation in society. Our society needs the active presence and use of women's talents and abilities in different economic, social, political and cultural fields. In such a society, there is no place for shyness. However, modesty has a valuable and special place and all people consider lots of value for it. (Women's Message 1382)

\section{Know about the Signs of Shyness}

Shyness as disorder has some signs and the shy person has the following characteristics: he/she cannot talk to others appropriately, and is unable to express what he/she means, suffers from Tongue tie in groups, is Secluded, likes being alone and escapes from society, cannot ask his/her questions, cannot defend his/her rights, speaks discretely and cannot answer his/her lessons. Shyness is a disorder that is in the form of depression when the person escapes from interaction and communication with others. If it is not treated, it will be turned into more important diseases. If shyness continues, it will become a bigger shyness and the person cannot achieve social skills and consequently he /she cannot find a job or communicate with others. Usually, shy and quiet people are encouraged and appreciated but there is a sense of incompetence and insecurity inside these people. Thus, they have psychological problems, create a negative image from themselves in their minds, have phobia, anxiety and fear, and are used to chew their nails, suffer from Tongue tie, lose themselves while speaking and forget about what that was going to say. (Ofogh Hawzah 1381)

\section{Do Not Underestimate Teaching Social Skills}

One of the main problems of people is the lack of social skills to communicate. Shy people think that interpersonal relations may cause some problems for them. Shy People have high expectations in interpersonal relations. They are socially anxious and consider unreal and high expectations for themselves and others. (Rajabi and Abbasi 1389) They did not learn social skills or appropriate relations with others ort taught them Incompletly since childhood. Thus, they have an inability to establish healthy relationships while in adulthood or feel weakness. (Bazk 1376) Dokaneyi Fard (1386) in his study with the subject of the effect of teaching life skills on the increase of self confidence and decrease of shyness in university students that was done on 30 girls and 30 boys concluded that teaching life skills reduces shyness and has a very good effect on it. Thus, it can be claimed that the lack of dominance on life and social skills has a significant effect on the growth and incidence of shyness.

\section{Stop Too Much Care, Let Them Speak and be Comfortable}

Fear and shyness are the result of parents' Indulgence in taking care of children. Some parents think that their children are very valuable assets that should be taken care in order to be safe from the bad behavior and Morality of other children. They limit the behavior and speech of their children to ethical obligations. Therefore, these children express fewer ideas or do something directly due to the fear of making a mistake. For this reason, when they face a stranger they become nervous. (Ranje Bazou 1368) In a study entitled the relationship between communicative patterns of family and shyness in teenagers that was done on 367 Tehrani students, it was concluded that the communicative patterns of family have a significant effect on children's shyness. In the families in which parents do not let their children to participate in discussions and decision making, children learn that their beliefs, attitudes and decisions are not important and should follow and obey their parents. In such families, children cannot express their beliefs and ideas that is a sign of their shyness. (Farahati et al 1389)

Also, in a study entitled as the relationship between the Parenting styles of parents and shyness with creativity in Gifted schools that was done on 237 female students in Tehran city, it was concluded that most students who were brought up by Authoritative parenting styles have low levels of shyness. The children who were brought up by appropriate parenting styles have low shyness than those who were affected by inappropriate methods. (Farahini et al 1392)

\section{Do Not be Shy to Prevent Shyness in Children}

Children are very amazing model receivers; they model us when they see that we are shy. Parents as the most popular (favorite) and effective behavioral model are seriously involved in teaching and strengthening social skills or the incidence 
of shyness because children model the behavioral patterns of adults directly or indirectly in different family situations. Thus, there is no doubt that families are responsible for the treatment of shyness more than others and even Therapists. Family teaches social and life skills to children. These skills strengthen self confidence and self respect in children. (Muhammadi Saif 1391) Family is the first environment where children become aware of the quality of human relations and grow. Parents' shyness is highly related to the shyness of the first child. Parents are better to treat their shyness in order to not have an effect on their children. (Darvizeh and Azadi 1389) For this purpose, make children aware of those times when you behave in a shy or shy way. (Bashirpour 1392)

\section{Stop Blaming in Front of Others}

One of the factors that highly create the spirit of shyness in human is blaming in front of others. Imam Ali (AS) stated that: نصحك فى الملا تقريع : Mentoring a person in front of others becomes rebuke and reprimand and thus makes his/her personality unstable. It is obvious that the person with damaged personality loses normal brevity and suffers from shyness. He/she has always doubts on doing things and does not have enough courage. On the other hand, mocking children causes ego death. Obviously, such a person will not be able to use his/her talents, thus he/she will lose brevity in life. (Rashidpour 1368)

\section{Helping the Increase of Self Confidence}

Shy children have a negative self image in their minds and feel that they are not accepted by anyone. For this reason, you should strengthen friend finding methods in them and encourage them to start friend finding. Through the Induction of abilities and reminding their positive features try to encourage them whenever they do a positive and valuable thing. Never ask them something beyond their abilities,. Studies show that the children who have a good feeling toward themselves have less shyness. (Muhammadi Saif 1391) Shy people do not believe in themselves and do not know about their potential talents. Thus, they underestimate themselves and have fear and anxiety while facing others. Shy people consider themselves as so much less than they are and think that the others' opinion is negative about the, shy people often hide themselves from strangers and become nervous while speaking or play with their fingers and clothes. They like to communicate with the people who are at a lower level in terms of age, academic conditions and etc. to not feel shortage and humility. (Shayested Nejad 1392) As the result of the study of Behpajuh and Hejazi (1386) showed, most children can make us to have a better or worse feeling toward ourselves. If the person has a positive evaluation of his/her performance, it will increase his/her self confidence. As the study of Reza Pour Mir Saleh et al (1391) showed, teaching the skills of assertiveness and self confidence in shy students.

\section{Discussion and Conclusion}

According to what was said, shyness should not be mixed up with modesty. We also should not encourage the quiet people, consider them as more modest people and consider this behavior positive. Then, it is necessary for parents to recognize the signs of shyness because one of the first steps to treat shyness is to recognize those signs. It is very important to teach social skills to children and communicative models of family has an important effect on personality traits of teenagers because those people who have poor social skills always consider themselves weak and this issue caused the incidence of shyness in them. Sometimes shyness is the result of Indulgence of parents in taking care of their children. These parents think that they should take care of their children as objects and do not let them to make decision. This issue makes children to not speak and say his/her words and causes shyness in them. Another issue is the shyness of parents that causes the incidence of shyness in children because children are very amazing model receivers they know how their parents behave. Thus they should pay attention to parents to not suffer from shyness. Another raised issue was blaming children in front of others. Some parents are used to blame their children in front of others when they made a mistake. Thus, their children will be hurt and lose their normal brevity and suffer from shyness. Helping the increase of self confidence can be a miraculous treatment because it makes children to trust themselves, destroy the negative image of themselves in their minds, better recognize their potential talents, develop them and not make doubt about their courage. 


\section{References}

Afrouz Gh, (1381), "The Psychology of shyness and therapies. Tehran: Islamic culture.

Ofogh Hawzah (1381); "consultation", Ofogh Hawzah, 16, 7

Bazl M, (1376): "Consultation and Education: shyness and how to fix it," Avicenna's Philosophy, 2, 31

Bashirpour M, (1392); " shyness in students, growth of School Counselor, 31, 17

Beh Pajouh, Hejazi M, (1386) "group assertive training program impact in increasing assertiveness and self-esteem of students with low assertion", consultancy research, 23, 20

Women's Message (1382); "a social anxiety in women and girls", Women's Message, 134, 48

Darvizeh Z, Azadi Sh, (1389); "the relationship between parenting style shyness in girls high schools Noorabad mamasani" Woman and Society, 2, 47-49

Dokaneyi Fard F, (1383), "The effect of life skills training to increase self-esteem and shyness reduce students' new ideas in education, 7,53

Rajabi Gh, Abbasi Gh, (1389); "factor structure (construct validity) Persian version of the revised shyness among students", psychiatry and clinical psychology, $16(4), 465$

Rashidpour M, (1368): "The causes of shyness in children" link, 123, 5-6

Reza Pour Mir Saleh Y, Abu Torabi Kashani P, Ebrahimi Ghavam S. (1391) "The effect of increasing assertiveness skills, assertiveness and self-esteem in third grade to fifth-grade girl students with low assertion of Tehran", clinical psychology and personality, 7, 77

Ranjebazou K, (1368), "the shy child", link, 119, 82

Saidi, A. (1355); "shyness must be overcomes," Wahid Journal, 200, 704-705

Salahshour M (15/08/1394), ashamed of shyness in children; yon.ir/4K5C

Shayeste Nejad A (1392); "some causes of shyness and recommendations for its prevention", link, 413, 28

Farahati M, Fathi Ashtiani A., Moradi, A., (1389), "The relationship between family communication patterns and shyness in adolescents' psychological health research, 4 (1 and 2), 50-51

Farahini N, Afrouz Gh, Rasouolzade Tabatabaei K, (1392), "The relationship between parenting practices and shyness with creativity in gifted schools", School Psychology, 2 (4), 137-147

Kalhori, M. (1389), "Children's shyness and isolation," Teacher Development, 250, 7071

Muhammadi Saif, M. (1391): "How to deal with shyness in children? (Part I)", Women's message, 248, 60

Muhammadi Saif, M. (1391): "How to deal with shyness in children? (Part II)", Women's message, 249, 60

Morad Hasel, M. (1382); "narrative experiences crossroads of adolescence: isolation, shyness and isolation", link, 291, 31 


\title{
The impact of Lean Thinking on Organizational Learning Case Study: SAIPA Automobile Manufacturing Group
}

\author{
Atena Aghakhani \\ Master of Technology Management, Department of Technology Management, Faculty of Management and Accounting, \\ Tehran South Branch, Islamic Azad University, Tehran, Iran \\ Email: aghakhani.atena@gmail.com \\ *P.h.D. Golamreza Hashemzadeh Khoorasgani \\ Assistant Professor, Department of Technology ,Management, Faculty of Management and Accounting, \\ Tehran South Branch, Islamic Azad University, Tehran \\ Email: Gh_hashemzadeh@azad.ac.ir

\section{P.h.D. Ashraf Shahmansoury} \\ Assistant Professor, Department of Technology Management, Faculty of Management and Accounting, \\ Tehran South Branch, Islamic Azad University, Tehran \\ Email: shahmansoury92@gmail.com
}

\author{
Doi:10.5901/mjss.2016.v7n4s1p219
}

\begin{abstract}
Lean thinking is an approach to increase continuous value creating and productivity as well as minimizing the costs and losses. Further, organizational learning is defined as a set of measures such as knowledge acquisition, information distribution, information and memory interpretation, which consciously or unconsciously affect the positive organizational development. This research aimed at studying the impact of lean thinking on the organizational learning. The study has used a questionnaire to measure variables. Lean thinking is tested through twenty-eight items; and organizational learning is tested by five items of shared vision, organizational learning culture, teamwork and group learning, knowledge sharing and participative leadership. The questionnaires were distributed among one-hundred and thirty-two managers and staffs of the center for strategic planning and studies and department of planning and excellence development management in SAIPA automobile manufacturing group'. The education level of the participants was higher than a bachelor degree. SPSS software was used to analyze the data. Results showed that lean thinking has a positive impact on organizational learning. Also, lean thinking has a positive and significant impact on all aspects of organizational learning.
\end{abstract}

Keywords: Lean Thinking, Organizational Learning, Organizational Knowledge

\section{Introduction}

One of the important features of humanity is the ability to learn and think and individuals learn it before entering to the organization. But, there is a debate on those knowledge and skills that individuals learn after entering the organization, which they are referred as the organizational learning. Organizational learning is generally concerned with processes in which practical knowledge and information are arisen; shared; interpreted and institutionalized in the organization (Qurbani Zade and Asad Pour, 2010). An organization, whose managers and staffs can learn and think well, is able to achieve organizational goals. Lean thinking is the most powerful tool and the only tool available for creating value as well as loss avoidance in any organization. Lean thinking is provided a manner by which can determine the value. Then, it could be possible to put value-creating activities in the best sequence and these activities should be implemented immediately whenever they are required so that they would have the greatest impact (Taqi Zade and Shateri, 2009). The fundamental concept of lean thinking has lied in eradicating loss and creating value in the organization. Lean thinking is an approach to increase continuous value creating and productivity as well as minimizing the costs and losses. This thinking provides a manner through which it could be possible to get the highest by using fewer resources, less

1 SAIPA group 
equipment, time and space and get close to customers with respect to the customers' needs while meeting their needs. Also, executing the lean manufacturing system in the organization would be possible through this kind of approach. Substantial reduction of costs, enhancement of product's quality, timely delivery of products and services to the customers, enhancement of staff safety and improvement of labor condition are examples of productive processes. An organization is able to achieve the regarded objectives that its ongoing processes are produced at an admissible level. Organizations can make their processes productive by putting forward the lean thinking model. Lean thinking should become a culture in the organization and it should be noted that whatever the commitment and engagement with the basic values and the core members of the organization be more as well as more members believed in the values, the culture and values will be stronger and they will have a greater impact on the behavior of the organization members. Besides, organization members need to recognize the cultural values for accepting them. Therefore, the first practical measure for grounding the institutionalization of lean thinking in an organization is teaching these concepts to its staff and believing that change in the results means that individuals must change their behavior and to do that they must change their thinking. Since, everything comes from human thought, not the technology or knowledge, humanity fits into the center of the system based on the modern manufacturing practices and gives sense and meaning to it. Of course, it is better to use the term "learning" instead of teaching. Teaching refers to guiding something; it means controlling; but learning means strengthening ability through an experience that is obtained by following affairs. Learning always is obtained over time and in the path of real life. This kind of learning is very difficult to control, but it produces a sustainable knowledge and enables learner has an effective behavior when dealing with various situations. A learning organization is the one that has captured all intellectual power, knowledge and experience of organization for continuous improvement, change and development. Organizational learning is all the procedures, mechanisms and processes that are used within the organization in order to realize the learning. Organizational learning is obtained through sharing insight, knowledge, experience and mental models of its members. In general, the ability of an organization is detecting errors and correcting them as well as changing its knowledge and values so that it develops new problem-solving skills and new capacity for working. While we must be able to direct the individuals' attitudes toward lean thinking in order to reach out to the less loss; motivate for learning more in the organization; keep pace with changes and achieve success; find ways to achieve the goal and finally find a shortcut to get the highest in the competitive market.

The question is that how is the relationship between organizational learning in its classic sense and lean thinking in its modern improved form.

It should be realized that lean thinking is followed by organizational learning and in order to achieve its objective better and given the history of its using, there are some drawbacks; although it was successful in this field. Lean thinking is focused more on productivity and prevented risk-taking and innovation. But according to the recent developments in the kind of lean thinking, this study examines whether these drawbacks exist or not? This research has sought to claim that lean thinking, however, is more based on the productivity approach at the operational level; but it is on the basis of heuristic approach at the strategic level. Thus, their influence on each other will provide more backgrounds for learning through productivity. This study argues that organizations need to balance between the use of lean and learning concepts through exploration to become lean without endangering the innovation ability. Therefore, it aimed at investigating and evaluating the implementation of lean concepts from the organizational learning perspective.

\section{Theoretical Framework and Review of Literature}

\subsection{Organizational Learning}

With the development of science and technology and the expansion of business areas including virtual organizations, enterprises are expanded and business environment has become into a challenging and competitive environment and new paradigms have emerged that makes surviving difficult for many firms. Transformation of competitive advantages is normal in such an environment. Learning is considered as the greatest competitive advantage in new paradigms of business. Hence, learning is located at the center of the new paradigm (Salajeqe and Nazeri, 2010). Organizational learning is studied by approaches of psychology, sociology, organizational theory and strategic management due to its importance for the survival, growth, success and excellence (Xorshid and Pasha Zade, 2014). Today's organizations are in a complex and changing environment. So that, they are no longer able to predict the future condition. Learner organizations are so courageous and empowered that their foundation is based on learning; and they consider long-term learning as the best way to improve the performance (Sharifi and Islamie, 2008). 


\subsubsection{Organizational Learning Process}

According to Figueiredo learning in organizations involves four secondary processes, which are acquiring the knowledge from outside of the organization, acquiring the knowledge within the organization, generalizing the knowledge, and encrypting and developing the knowledge. According to many authors, such as Huber, Slater and Narver, organizational learning is a process which is composed of three different stages as follows: 1. The acquisition (production) of information, 2. The publication and distribution of information, and 3. A common interpretation. Organizational learning is defined as way during which organizations produce, complete and organize the knowledge, and normalize their activities based on it and enter it into their culture (Qorbani Zade and Asadpour, 2010). According to scholars and theorists, it can be outlined four basic steps in the process of organizational learning, which are as follows:

1. The Acquisition of Knowledge: Management controls the key indicator for organizational performance, constantly. Management learns new items through direct observation of phenomena and events. Management enjoys the experience of partners, suppliers and customers in order to learn more. Management uses the feedbacks that are obtained from the previous experiences of the company. The company employs expert and intelligent people.

2. The Distribution of Information: when an individual needs some information, does he know exactly by whom and which way he could access to the information? Staffs are well aware that their knowledge serves in what areas of the company. Staffs make extensive use of information systems in their works. Staffs provide their information and documentations (such as useful statistics, new ideas and plans) for others. Management has paid adequate attention to the main strategies of competitors.

3. The Interpretation of Information: staffs have a wide range of communication means (such as phone, e-mail, Internet and Intranet) at their disposal. Staffs are encouraged to communicate clearly with each other. Company staffs do not resist against the new working methods. Management makes the outdated information out of access from staffs. The company acts quickly to respond to the technological changes.

4. Organizational Memory: Staffs use electronic equipment for communication. Staffs refer to data archive for their decisions. The company provides the required information and documentation with all the details for use in the current affairs. There are certain procedures in the company to manage and access the information (A'raabi and Faxaarian, 2008).

\subsection{Lean Thinking}

The era in which we live now is customer-oriented and audience-centered. It means that the success of any organization is directly related to the level of its attention to the customer and its needs. In this regard, it is essential to improve comprehensibility at the organization level to be able to meet customer needs. Researches have shown that it should just enterprise a small fraction of the spent time and efforts in the organization. According to the previous researches, just a small part of the consumed time and effort in the organization create value for customers. Therefore, identification of loss sources and search for solutions to eliminate and modify the constraints and convert it to value adding subjects have been focused by managers (Taqizade et al, 2010).

Lean is a systematic approach to identify and eliminate loss through continuous improvement and flowing out the product by customers in order to achieve perfection. This philosophy seeks to perfection and making flawless manufacturing systems. Principles of lean manufacturing, consider unlimited objectives for the system such as continuous descent final price, zero losses, endless variety of products, reducing preparation time and ultimately, increasing customer satisfaction (Modi and Thakkar, 2014). This manufacturing method using a philosophy of continuous improvement and teamwork culture has tried to analyze the losses in the process of manufacturing and eliminate them (Moradian Brojeni et al,. 2014). Lean reduces the time, which is spent since the customer order till transportation and it eliminates anything caused increasing at the time and cost (Modi and Thakkar, 2014). Lean thinking is an inference governance method to improve efficiency, effectiveness and quality of products and services. In recent years, the U.S. and Japanese management experts have developed the ideas and methods of lean thinking. This management technique is employed in the aerospace industry and in the automobile sector. In the industrial sector, these concepts are classified as making the highest performance and global industries (Taqizade et I,. 2010).

\subsubsection{The Principles of Lean Thinking}

Non-visibility is the most essential problem of the lean thinking and it is a bit difficult to understand it at the first exposure; but its concepts will be revealed by conducting a little research on the subject. There are five fundamental principles of 
lean thinking, which should be followed step by step to get the maximum profit. These principles are as follows:

1. Accurate Determination of the Value of any Certain Product: Identifying the value of activities that create value for the final product.

2. Identifying the Value Stream for Product: Identifying all actions required to design, order and make a certain product.

3. Moving without Interrupting in the Value: Ensure that there is a continuous stream in the process.

4. Establishing a Tensile Structure System: Allowing the customer to extract the value from the manufacturer.

5. Pursuing Perfection: Offering a product according to the customer needs and expectations in the agreed timetable under ideal conditions without error and shortcoming (Aziz and Hafiz, 2013).

In this regard, there are various studies, which are discussed in the following:

Moraadian Brojeni et al (2014) in a research entitled "Manufacturing and Distributing in the Three-level Supply Chain based on the Lean Thinking by GA Approach", reported that today, organizations should provide various products according to the customers' demands in order to remain in the competition arena; therefore, they require themselves to manage the external resources in addition to the internal resources of their organization and enters into categories such as supply chain management. On the other hand, a complete success and excellence of these chains requires a focus on value creation and customer orientation; thus, it is so essential to lean the chain, organizations and their processes. Amirxani et al (2012) has conducted a study titled "Evaluation of Leanness in Iran Khodro based on the Jackson and Jones Model". This research has investigated Iran Khodro's condition in terms of Leanness level and they have reminded the necessity of implementing the process of revitalization and cycle of strategic improvement to take steps towards modifying consumption patterns, especially in the country's energy consumption, and for country's strategies, in addition to increasing the product quality, which is toward competitiveness. The results of data analysis using the structural equation model indicated that three vertices of development have a strong relation with each other; and in turn, these vertices could have a significant impact on the development of Iran Khodro. Finally, the Friedman test was used to determine the priority and importance of development nine keys in Iran Khodro. Lee et al (2015) has conducted a study entitled "An Empirical Research in the Relation between Corporate Organizational Learning and Organizational Culture: A Case Study of Insurance Industry in Taiwan Region". Their results showed that organizational culture significantly associated with the organizational learning and organizational culture and organizational learning views explains the prediction and influences on each other. Farrox et al (2015) in a study titled "Learning Organization and Competitive Advantage as an Integrated Approach", have stated that learning is done through its members; and totally, it is making a competitive advantage by developing a facilitating system and through its development process and sharing information to empower staff. Nenni et al (2014) has conducted a research entitled "Improving Operations through a Lean Management Approach: A Case Study of Pharmaceutical Industry". This paper aims to show the positive effect of a lean management approach to increase productivity, even in a company that is in crisis.

\section{Objectives of the Study}

The intended objectives of this study are as follows:

- The Main Objective

- Studying the effect of lean thinking on the organizational learning

- The Secondary Objectives

- Studying the effect of lean thinking on the shared vision

- Studying the effect of lean thinking on the organizational learning culture

- Studying the effect of lean thinking on the teamwork and group learning

- Studying the effect of lean thinking on the knowledge sharing

- Studying the effect of lean thinking on the participative leadership

\section{Methodology}

This is a cross-sectional and practical study. Questionnaires are used to measure the variables. Lean thinking with twenty-eight items and organizational learning also with five dimensions of shared vision, learning culture, teamwork and group learning, knowledge sharing and participative leadership were measured. The questionnaires were distributed among one-hundred and thirty-two managers and staffs of the center for strategic planning and studies and department of planning and excellence development management in SAIPA group. The education level of the participants was higher than a bachelor degree. SPSS 20 software was used to analyze the data. 


\section{Findings}

\subsection{Descriptive Statistics}

The descriptive statistics are as follows:

In terms of sex, $58.59 \%$ of respondents were men and $41.41 \%$ were women. In terms of education level, $37.5 \%$ had bachelor degree, $56.3 \%$ had master degree and 6.3\% had a Ph.D. degree. In terms of job experience, $10.4 \%$ had less than five years job experience, 27.1 had a job experience between five to ten years, $33.3 \%$ had between ten to fifteen years job experience, $20.8 \%$ had between fifteen to twenty years job experience and $8.3 \%$ had more than twenty years job experience.

\subsection{Inferential Findings}

\section{Evaluating the Research Hypotheses}

\subsection{The Main Hypothesis: Lean thinking has a significant impact on the organizational learning.}

Table 1. Summary of the Model in the Main Hypothesis

\begin{tabular}{|c|c|c|c|c|c|}
\hline Correlation Coefficient & The Coefficient of Determination & Durbin-Watson & F Statistic & Beta Coefficient & Sig. \\
\hline $\mathbf{0 . 4 5 5}$ & 0.207 & 1.970 & 12.518 & 0.455 & $0.001^{\mathrm{b}}$ \\
\hline
\end{tabular}

According to table 1 , determination coefficient of 0.207 was calculated by examining the relationship between lean thinking and organizational learning. This means that the independent variable determines the $20.7 \%$ of changes in the dependent variable. Also, the value of Durbin-Watson represents the independence in variables' errors to each other. According to the obtained $\mathrm{F}$ value of 12.518 and the significance level of 0.001 , it can be concluded that $\mathrm{H} 1$ is accepted and lean thinking has a significant impact on the organizational learning. The beta coefficient of 0.455 between two variables indicates that the lean thinking effect on the organizational learning is at the average level.

\subsection{First Sub-hypothesis: Shared vision has a significant impact on the organizational learning.}

Table 2. Summary of the Model in the First Sub-Hypotheses

\begin{tabular}{|c|c|c|c|c|c|}
\hline Correlation Coefficient & The Coefficient of Determination & Durbin-Watson & F Statistic & Beta Coefficient & Sig. \\
\hline $\mathbf{0 . 6 7 5}$ & 0.456 & 1.970 & 40.273 & 0.675 & $0.001^{\mathrm{b}}$ \\
\hline
\end{tabular}

According to table 2, determination coefficient of 0.457 was calculated by examining the relationship between lean thinking and shared vision. This means that the independent variable determines the $45.6 \%$ of changes in the dependent variable. Also, the value of Durbin-Watson represents the independence in variables' errors to each other. According to the obtained $F$ value of 40.273 and the significance level of 0.000 , it can be concluded that $\mathrm{H} 1$ is accepted and lean thinking is influential. The beta coefficient of 0.675 between two variables indicates that the lean thinking effect on the organizational learning is at the fair level.

\subsection{Second Sub-hypothesis: Organizational learning culture has a significant impact on the organizational learning.}

Table 3. Summary of the Model in the Second Sub-Hypotheses

\begin{tabular}{|c|c|c|c|c|c|}
\hline Correlation Coefficient & The Coefficient of Determination & Durbin-Watson & F Statistic & Beta Coefficient & Sig. \\
\hline $\mathbf{0 . 8 0 0}$ & 0.639 & 1.970 & 85.148 & 0.800 & $0.001^{\mathrm{b}}$ \\
\hline
\end{tabular}

According to table 3 , determination coefficient of 0.639 was calculated by examining the relationship between lean thinking and organizational learning culture. This means that the independent variable determines the $63.9 \%$ of changes in the dependent variable. Also, the value of Durbin-Watson represents the independence in variables' errors to each 
other. According to the obtained $\mathrm{F}$ value of 85.148 and the significance level of 0.000 , it can be concluded that $\mathrm{H} 1$ is accepted and lean thinking has a significant impact on the organizational learning culture. The beta coefficient of 0.800 between two variables indicates that the lean thinking effect on the organizational learning is at the excellent level.

\subsection{Third Sub-hypothesis: Lean thinking has a significant impact on the teamwork and group learning.}

Table 4. Summary of the Model in the Third Sub-Hypotheses

\begin{tabular}{|c|c|c|c|c|c|}
\hline Correlation Coefficient & The Coefficient of Determination & Durbin-Watson & F Statistic & Beta Coefficient & Sig. \\
\hline $\mathbf{0 . 6 1 6}$ & 0.379 & 1.970 & 29.341 & 0.616 & $0.001^{\mathrm{b}}$ \\
\hline
\end{tabular}

According to table 4 , determination coefficient of 0.639 was calculated by examining the relationship between lean thinking and teamwork and group learning. This means that the independent variable determines the $63.9 \%$ of changes in the dependent variable. Also, the value of Durbin-Watson represents the independence in variables' errors to each other. According to the obtained $F$ value of 29.341 and the significance level of 0.000 , it can be concluded that $\mathrm{H} 1$ is accepted and lean thinking is influential on teamwork and group learning. The beta coefficient of 0.616 between two variables indicates that the lean thinking effect on the organizational learning is at the fair level.

\subsection{Fourth Sub-hypothesis: Lean thinking has a significant impact on the knowledge sharing.}

Table 5. Summary of the Model in the Fourth Sub-Hypotheses

\begin{tabular}{|c|c|c|c|c|c|}
\hline Correlation Coefficient & The Coefficient of Determination & Durbin-Watson & F Statistic & Beta Coefficient & Sig. \\
\hline $\mathbf{0 . 7 4 8}$ & 0.560 & 1.970 & 61.035 & 0.748 & $0.001^{\mathrm{b}}$ \\
\hline
\end{tabular}

According to table 5 , determination coefficient of 0.560 was calculated by examining the relationship between knowledge sharing. This means that the independent variable determines the $56 \%$ of changes in the dependent variable. Also, the value of Durbin-Watson represents the independence in variables' errors to each other. According to the obtained $F$ value of 61.035 and the significance level of 0.000 , it can be concluded that $\mathrm{H} 1$ is accepted and lean thinking is influential on knowledge sharing. The beta coefficient of 0.748 between two variables indicates that the lean thinking effect on the knowledge sharing is at the fair level.

\subsection{Fifth Sub-hypothesis: Lean thinking has a significant impact on the participative leadership.}

Table 6. Summary of the Model in the Fifth Sub-Hypotheses

\begin{tabular}{|c|c|c|c|c|c|}
\hline Correlation Coefficient & The Coefficient of Determination & Durbin-Watson & F Statistic & Beta Coefficient & Sig. \\
\hline $\mathbf{0 . 7 9 9}$ & 0.638 & 1.970 & 84.614 & 0.799 & $0.000^{\mathrm{b}}$ \\
\hline
\end{tabular}

According to the table 6 , determination coefficient of 0.638 was calculated by examining the relationship between lean thinking and participative leadership. This means that the independent variable determines the $63.8 \%$ of changes in the dependent variable. Also, the value of Durbin-Watson represents the independence in variables' errors to each other. According to the obtained $\mathrm{F}$ value of 84.614 and the significance level of 0.000 , it can be concluded that $\mathrm{H} 1$ is accepted and lean thinking is influential on participative leadership. The beta coefficient of 0.799 between two variables indicates that the lean thinking effect on the participative leadership is at the fair level.

\section{Conclusion and Suggestions}

The results of evaluating the main hypothesis indicated that lean thinking is influential in the organizational learning. So, it can be concluded that the organizational learning can be promoted by improving the environment of lean thinking in the organization. In this regard, the following suggestions are offered:

1. It is recommended to create a space in the organization that staffs and organization find their profit in customer satisfaction. 
2. Provide the process mapping to clarify the company's current situation.

3. Processes should be improved and staffs be trained to minimize the losses in the manufacturing processes.

4. Participation of customers and consultation with them in designing and development of the organization products caused that goods be produced according to their taste.

The fundamental concept of lean thinking has lied in eradicating loss and creating value in the organization. Lean thinking is an approach to increase continuous value creating and productivity as well as minimizing the costs and losses. This thinking provides a manner through which it could be possible to get the highest by using fewer resources, less equipment, time and space and get close to customers with respect to the customers' needs while meeting their needs. Through this kind of approach can execute the lean manufacturing system in the organization.

After evaluating the first sub-hypothesis, it was found that lean thinking has a significant impact on the shared vision of staffs. So, it is recommended to SAIPA to take steps toward creating a shared vision by considering the lean thinking.

After evaluating the second sub-hypothesis, it became clear that lean thinking has a significant impact on organizational learning culture. Lean thinking is a systematic approach to identify and eliminate loss through continuous improvement and flowing out the product by customers in order to achieve perfection. This philosophy seeks to perfection and making flawless manufacturing systems. Principles of lean manufacturing, consider unlimited objectives for the system such as continuous descent final price, zero losses, endless variety of products, reducing preparation time and ultimately, increasing customer satisfaction. This manufacturing method using a philosophy of continuous improvement and teamwork culture has tried to analyze the losses in the process of manufacturing and eliminate them. So, it is recommended to strengthen the learning culture by improving the level of customer satisfaction in SAIPA group and meeting their expectations as well as by continuous improvement and emphasizing on the teamwork.

After evaluating the third sub-hypothesis, it was found that lean thinking has a significant impact on the teamwork and group learning. Therefore, it can be said that workspace and group learning can be strengthened and improved by implementing and strengthening the principles of lean thinking in the organization. Lean thinking is a way to understand the problems; it is a way to identify the causes of difficulties; it is an attitude for using scientific methods to define a system of values and focusing on the improvement and innovation of value creation streams in the direction of excellence and perfection. Lean thinking is an intelligent review on the value and its stream with minimal changes in the organizational foundations with the lowest cost.

The result of evaluating the fourth sub-hypothesis showed that lean thinking has a significant impact on the knowledge sharing in the organization. Many factors influence the process of knowledge sharing in the organization. These factors can be classified into four general categories of human factors, cultural factors, structural factors and technological factors. Given the extent of the factors affecting the knowledge sharing process, this study has tried to examine the subject from the human factor perspective. The voluntary dissemination of skills and experiences in other parts of the organization is considered as one of the human factors, which affects the knowledge sharing. Although, knowledge is available at three levels of individual, group and organizational, knowledge sharing at the individual level is more important for the organization since the organizational knowledge is formed on the basis of individuals' knowledge. If individual knowledge is not available for others, then it will not affect the organization (Lu and Naji, 2008). At the individual level, knowledge sharing barriers are of two types: barriers that affect the ability to share knowledge and those that affect the enthusiasm for working. The ability to share knowledge largely depends on the individual's talent in his/her communication and social behavior. On the other hand, for example, enthusiasm is affected by many factors. Personal characteristics of individuals are the individual factors affecting the knowledge sharing. Implementation of lean thinking can influence the knowledge sharing.

After evaluating the fifth sub-hypothesis, it became clear that lean thinking has a significant impact on the participative leadership. Change is inevitable and it should be designed and managed to establish a constructive and effective development in organizations. There is a growing need for that kind of leadership in the today's world. This leadership prices to establish organizations that activated their potentials; while, think about solving crises and emergency situations in the work environment. In such conditions, organizations should know that they have to prefer objectives of "become" to "remain" for achieving the future authority. In other words, development, reconstruction and modernization are as one of the important aspects of organizational health in the present era. Therefore, the management of change in organizations is one of the hardest tasks of leading managers. Participative leading transmits the burden of governance from the shoulders of a body or a limited group to the shoulders of a larger society by mobilizing the thoughts and empowering the staffs and nurtures the collective wisdom of the group and increases their commitment and attachment to the work. Participative leadership paves the way for cooperation, sympathy and empathy among employees and makes the link between them and the organization stronger. This method through participating the 
staffs in governing the organization's affairs provides a context in which they could increase the quality and quantity of their assistances by acquiring more and better behavioral and performance capabilities and abilities and know the organization's success as their own. Participative leadership as an approach to human resources, is considered the slogan of "proper people, at the proper time and for the proper work" as the frontispiece of its activities. This slogan, which is discussed in the participative leadership, is one of the principles of lean thinking. Thus, it would be possible to take positive and useful steps toward improving participative leadership.

\section{References}

A'raabi, M. and Faxaarian, M. (2008). "Measurement of Organizational Learning: a Case Study of Subsidiaries of Iran Diary Industries", Management Researches, 109-129.

Taqizade, H.; Taari, Q and Orangi, S. (2010). "Determination of Manufacturing Organizations' Compliance with the Principles of Lean Thinking: a Case Study of Tractor Manufacturing Company of Tabriz, Iran", Journal of Industrial Management, Faculty of Humanities, Islamic Azad University of Sanandaj, 42-54.

Taqizade, H.; Soltani Fasqandis, Q. (2010). "The Evaluation of the Learnability Level of the Organization by using Fuzzy Expert System", Science and Research Journal of Modiriat-E-Farda, 1-20.

Xowrshid, S. and Pashazade, A'. (2014). "The Effect of Transformational Leadership Style on Organizational Learning Capability with regard to the Intermediary Role of Organizational Intelligence", Transformation Management Journal, 1-37.

Salajeqe, S. and Naazeri, M. (2010). "New Thinking, Learning Organizations in the Era of Management", Management Era Journal, $52-$ 58.

Sharifi, A. and Islamie, F. (2008). "Investigating the Relationship between Organizational Learning and the Use of ICTs in the Islamic Azad University of Garmsar in the Academic Years 2007/08, Quarterly Journal of New Approaches in Educational Administration, $1-22$.

Mohammadi Mogaddam, Y.; Qorbanizade, V. and Islami, A. (2012). "The Importance of Organizational Learning in the Dynamics of Organizational Knowledge Creation", Scientific-Promotional Journal, 1-24.

Moradian Brojeni, P.; Sadeqie, A. and Faxzarzad, M. (2014). " Manufacturing and Distributing in the Three-level Supply Chain based on the Lean Thinking by GA Approach", International Journal of Industrial Engineering and Production Management, 367-377.

Maso'di Nodoshan, A' and Javaan Sharq, H. (2005). "Organizational Learning and the Strategy for Establishing the Learning Organization", Journal of Informing, Educational and Research, 69-78. 


\title{
A Comparative Study of Lecture-Based and Multimedia-Based Training Method on the Second Year Students Competency in General Electronics Course in the Technical and Vocational School
}

\author{
Badri Afyouni \\ Graduate Student of ethic science in Education Curriculum \\ Email: afunib@gmail.com \\ Mino Tabatabai \\ Assistant Professor, PNU \\ Email:dmtabatabaie@yahoo.com \\ Ali Ghasempour \\ Assistant Professor, PNU \\ Email: alighasempoor@hotmail.com
}

Doi:10.5901/mjss.2016.v7n4s1p227

\section{Abstract}

The aim of this study was to investigate the effect of multimedia training method and lecture on second year students' competencies in General Electronics Course in technical and vocational school of Isfahan city. The research statistic population consisted of all second year students of technical and vocational school in the academic year 2015-2016. These two high schools were selected by random cluster sampling, data were collected from the tests and analyzed by using of covariance analysis. The results indicated that the electronic functional skills training score on multimedia-based group was significantly higher than lecture-based group. Also the students who were weak in electronics lessons have benefited significantly more than the stronger students from the multimedia-based training programs.

Keywords: multi-media method, lecture method, learning, students, competence

\section{Introduction}

Education is the basis and foundation for the growth and development of human resources. Creation of an educational system with the ability to train people to live in a changing world, is the important priorities of modern society. In this regard, the information technology are among the important achievements of recent decades that have a significant role in qualifying the teaching process and leads to the potential of improving learning results (Duncan and Cator, 2013).

Up to now the various results have obtained from many researches all over the world in relation to efficient training methods. (Molla zade, Kameli, Jafari Chogani, Mir Hosseini and Shojaa, 2015). One of the common methods of teaching is the lecture method that uses the expression orally (Azizi, 2003). Lecture is a fast, simple and inexpensive in the presentation. Today integrating the lecture with appropriate audiovisual equipment cause to increase the efficiency of this method. However many experts believe that if this method would desirably present can provide the effective learning and it is necessary that trainers use the lecture method in combination to other techniques for understanding the issues. (Shabani, 2010: Salimi, Shahbazi, Mojahed, Ahmadieh and Dehghan poor, 2008). Material that is presented in the lecture can be used for the person passively involved in the training process and however student in other methods such as problem solving or multimedia based training have the opportunity to participate in question actively and involve in various cases. (Gabr and Mohammed, 2011; Docherty, Hoy, Topp \& Trinder, 2005). In methods of multimedia training the content are given to the person and he should seek to learn and cope with solving the questions (Golshiri, Sharifi rad, Baghernejad, 2012). Fardanesh (2004) defines educational media as: "Media training are the tools to present comprehensive training and is naturally part of the learning and educational technology process, not all of it." He uses an analogy to define the above explanation: "If we call compressive as the consumer and the education as consumer goods, the media is the means that deliver the product from the production or distribution place to consumers. In other words, 
education, learning, goods, learner, consumer, and media are the tools for delivering the product to the consumer or to compressive education. According to the above analogy, we conclude that for example in many cases the main factor is teacher training, media training is also the teacher. If learning to be invited to a training program and receive all education from television, in this case training media is the television. So training media is a device or a factor that education is offered compressively through it. Training media are the physical means by which a training message is transmitted by them. (Ganiyeh Varizer, 1983, p. 5) .Media is a mechanism in which people learn through it, so enough time should be considered for its potential evaluation. This method involves activities that individuals can actively engage in learning personally and collectively. (Mir shahzadeh and Tootoonchi, 2008). Gardner (2003) discuss about the use of Assistive Technology in the interdisciplinary units of Special Education. He supports the improvement of teaching method by showing how to combine them in the curriculum and finally its positive effects by presenting examples of multimedia tools combination and software related to subjects as well as network activity to improve teaching methods. Studies have shown that multimedia-based education can help students' comprehension and retention (Capel, 2009; weeb and Anta, 2008). In fact, educational multimedia, are involved in media system due to their multi -sensory nature that can be easily adapted to a variety of learning styles and provide easy and stable learning by various forms of interaction. In addition, Scerri and Vacaner (1997) counted computer-based training advantages compared to traditional education (teachercentered) as providing immediate feedback, avoidance of subjective and biased judgments, facilitating individualized training process, given the increasing range of attention and motivation of learners, different learnings (Beach and Avayda, 1992). Multimedia application in educational situations has many advantages, some of which include: 1. the use of multiple senses for learning. 2. The more exercise to achieve domination, (3) facilitating participation for making relationship between concepts. 4. To facilitate the course repetition for re-application. 5. Effectiveness by economic points. 6. Flexibility of the program to the needs of learners (Razavi, 2008).

In recent years, despite the increasing media facilities in some schools with adequate financial capabilities, a lesser extent of multi-media teaching methods are used (Khorami rad, Heydariyan, Ahmari Tehrani, 2012). Education system in its transforming and exchanging operation, should change its teaching methods, in a way that the learners learn the content actively, and become engaged face to face with the issues and answer the question for solving the problems. (Soleymani pour 2004). But given that still the traditional educational methods and curricula are used in schools, it is necessary that the educational system change its methods so that students actively participate in educational programs; Therefore, techniques such as problem-solving, multimedia and ... should be taken into consideration (Shabani, 2006). one of the most important IT applications is multimedia training that is presented in on line learning formats in various forms such as computer -based learning and outline learning (Pawlowski \& Kozlov 2008).

The research findings indicate that virtual training and e-learning can help to the effectiveness of the teachinglearning process (Badrian et al, 2009; Momeni Rad, 2010; Chen et al., 2004). In addition, researches show that the use of computer simulations in testing, both in terms of learning and skill in conducting the same electronic circuit have a significant advantages in comparison with students who have worked in the lab with real tools. (Finkelstein et al., 2005), other examples of such research can be found in the work of researchers like Zacharia $(2007,2008)$, Klahr, Triona, And Williams (2006) and Denis Vavougios and Karakasidis (2008). Therefore, this research attempts to investigate the effect of multimedia application (Multi-SIM and Edison software) in general electronic course on students learning (competence).

By a review of studies it is specified that the results of studies have some contradiction on the effect of traditional learning methods and teaching electronics. (Badri, 2009; Momeni Rad, 2010; Chen et al., 2004) The lack of information in this research can be felt, that conducted on interactive and non-interactive multi-media effects on learning and concepts retention of electronic lesson. it was shown that interactive multimedia are more effective than non-interactive multimedia learning and retention (Sabbaghan et al, 2011: 156) This study aims at using teaching methods based on constructivism and Edison multi-wire software E5 version in the Virtual Lab on a general electronic course, to evaluate at first the different aspects of students learning curriculum and can remove the research gaps in this area and identify and assess the potential obstacles in effective usage of virtual labs and developer labs factors in electronic lessons.

By regarding that the curriculum electronic book (1) is new In the second year, many questions are provided to the students for which according to the time limit it is not possible to answer them (Zarifan and et al. 2014). The use of virtual software in simulation testing is one of the authors important recommendation about this curriculum, the effectiveness of virtual experiments in this study requires the scientific investigation. In total less studies are conducted on the effectiveness of constructivism approach in virtual training. By regarding what was said, this research by considering Edison multi-SIM software and general electronics lesson review its impact on learning in the second degree students of secondary (vocational) school. This study aimed to compare the practical skills learning in electronics lessons with lecture and software multimedia method in second degree student (son) of Vocational School that the hypothesis formulated 